\title{
Memory effect of polymer dispersed liquid crystal by hybridization with nanoclay
}

\author{
E. H. Jeong 1 , K. R. Sun ${ }^{2}$, M. C. Kang 1 , H. M. Jeong ${ }^{3}$, B. K. Kim² ${ }^{2}$ \\ ${ }^{1}$ National Core Research Center for Hybrid Materials Solution, Pusan National University, Busan 609-735, Korea \\ 2Department of Polymer Science and Engineering, Pusan National University, Busan 609-735, Korea \\ ${ }^{3}$ Department of Chemistry, University of Ulsan, Ulsan 680-749, Korea
}

Received 17 August 2009; accepted in revised form 20 October 2009

\begin{abstract}
The electro-optical performances of polymer dispersed liquid crystal (PDLC) were investigated in the presence of organically modified clays. With the addition and increasing amount of modified clay, driving voltage and memory effect, viz. transparent state of the film after the electricity is off simultaneously increased due most likely to the increased viscosity. Among the two types of modifier, 4-(4-aminophenyl) benzonitrile having greater chemical affinity with LC than hexylamine, gave finer dispersion of clay in liquid crystal, greater viscosity, larger driving voltage and response time, and greater memory effect.
\end{abstract}

Keywords: polymer composites, PDLC, polyurethane acrylates, clay, memory effect

\section{Introduction}

Polymer dispersed liquid crystals (PDLC) have been intensively studied as electro-optical display materials during the last few decades since they can be switched electrically from a light scattering state to a transparent state without polarizers and alignment layers [1, 2]. Improved electro-optical properties have been reported for new applications [3, 4]. Fan et al. [5] reported scattering-free PDLC for infrared light modulator. Nicoletta et al. [6] investigated application of PDLC for electro-chromic device by doping some electro-chromic materials. Regarding the electro-optic performance, low molar mass surfactant such as octanoic acid has also been used to reduce the operating voltage.

Nowadays, nanocomposites employing spatially confined liquid crystals are of great interest due to the prospects of their application in opto-electric devices, photonic crystals, depolarizers, scattering displays, information storage and recording devices and windows with adjustable transparency [7-10]. It has been shown that in such systems applied external electric field causes transparent state which under some conditions can be retained after the field is off, which is called memory effect [11]. The memory effect can be utilized for large area outdoor displays with high power consumption, which can significantly be reduced by utilizing the memory effect of PDLC with the field off.

For spherical aerosol particles, it has been found that essential contribution to the memory effect is achieved due to formation of ordered branched network of the aerosol particles in the liquid crystal matrix [12].

The present work reports the memory effect of modified clay in PDLC, where modification was made with two different organic surfactants, viz. 4-(4-aminophenyl) benzonitrile (AB), and hexylamine (HA), and the effect has been studied by scanning electron microscopy (SEM) morphology, 
contact angle, transmittance, switching voltage, response time of the film.

\section{Experimental}

\subsection{Materials and preparations of modified clay}

The sodium montmorillonite (MMT) having cation exchange capacity of $92.6 \mathrm{meq} / 100 \mathrm{~g}$ of the clay was purchased from the Southern Clay (Gonzales, TX). MMT was added to water / ethanol ( $75 / 25$ by vol\%) solution at $70^{\circ} \mathrm{C}$ and stirred for $4 \mathrm{~h}$. A 4-(4aminophenyl) benzonitrile (AB), and hexylamine (HA) (Figure 1) were respectively added to hydrochloric acid and stirred for $24 \mathrm{~h}$. The modified clay was filtered and washed repeatedly in the water/ethanol solution and dried for $12 \mathrm{~h}$.

a)

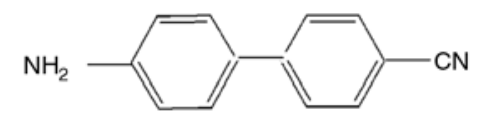

b) $\mathrm{CH}_{3}\left(\mathrm{CH}_{2}\right)_{5} \mathrm{NH}_{2}$

Figure 1. Chemical structures of clay modifiers: $\mathrm{AB}$ (a) and HA (b)

The LC-clay nanocomposite were prepared by dissolving a small amount $(0.5,1.0,1.5$ and $2.0 \mathrm{wt} \%)$ of clay in a commercially available cyano-based nematic LC mixture, E7 from Merck.

\subsection{Polyurethane prepolymer synthesis}

Bifunctional polypropylene glycol (PPG) having number average molecular weight of 750 was dried at $80^{\circ} \mathrm{C}, 0.1 \mathrm{~mm} \mathrm{Hg}$ for several hr until no bubbling was observed. Extra pure grade of hexamethylene diisocyanate (HDI) was used without further purifi- cations. Molar excess of HDI was reacted with PPG for over $1 \mathrm{~h}$ at $80^{\circ} \mathrm{C}$ to obtain NCO-terminated prepolymer. Then the reaction mixture was cooled down to $40^{\circ} \mathrm{C}$ and hydroxyl ethyl acrylate (HEA) was added to obtain HEA-capped polyurethane acylate (PUA) oligomers [13, 14]. Basic formulation to prepare the PUA oligomer is given in Table 1.

The PUA oligomers are highly viscous and immiscible with LC. To this 2-ethyl hexyl acrylate (EHA) and trimethylol propane triacrylate (TMPTA) were added to form a miscible mixture with LC, leading to a composition of oligomer/EHA/TMPTA $=4 / 2 / 4$ [15].

E7 (BL001, Merck), an eutectic mixture of three cyanobiphenyl and a cyanoterphenyl with $n_{0}=$ 1.5216, $n_{e}=1.7462$, and $\mathrm{TNI}=61^{\circ} \mathrm{C}$ was used as LC. LC-modified clay mixture was added to the prepolymer mixture at a fixed composition of LCmodified clay/prepolymer $=4 / 6$ by weight, together with a photo-initiator viz. Darocur 1173.

\subsection{Cell fabrication}

The reactive mixtures were mechanically mixed before they were filled into the indium-tin-oxide (ITO) coated cell by capillary action. Cell thickness was adjusted to $10 \mu \mathrm{m}$ using glass bead spacers. Then, the mixtures were cured using a UV crosslinker $\left(1.8 \mathrm{~mW} / \mathrm{cm}^{2}, 365 \mathrm{~nm}\right)$ to give three dimensionally networked PUA matrix. The UV cured PDLC films sandwiched between two ITO coated cells were placed normal to the direction of collimated beam of $\mathrm{He} / \mathrm{Ne}$ laser (wavelength of $632.8 \mathrm{~nm}$ ) to measure the electro-optical properties of the cell.

Table 1. Formulations for the preparation of PDLC films

\begin{tabular}{|c|c|c|c|c|c|c|c|c|}
\hline \multicolumn{3}{|c|}{ PU acrylate oligomer } & Dilluent & Virgin clay & Modifier & $\begin{array}{l}\text { Content of } \\
\text { clay [wt } \%]\end{array}$ & $\mathbf{L C}$ & Remark \\
\hline \multirow{7}{*}{ Polyol } & \multirow{7}{*}{ Diisocyanate } & \multirow{7}{*}{$\begin{array}{l}\text { End- } \\
\text { capping } \\
\text { acrylate }\end{array}$} & \multirow{7}{*}{ EHA } & \multirow{11}{*}{ Cloisite $\mathrm{Na}^{+}$} & \multirow{7}{*}{$\begin{array}{c}\text { Hexylamine } \\
\text { (HA) }\end{array}$} & 0.0 & \multirow{11}{*}{ E7 } & None \\
\hline & & & & & & 0.5 & & aDC05 \\
\hline & & & & & & 1.5 & & DC15 \\
\hline & & & & & & 0.5 & & HA05 \\
\hline & & & & & & 1.0 & & HA10 \\
\hline & & & & & & 1.5 & & HA15 \\
\hline & & & & & & 2.0 & & HA20 \\
\hline \multirow{4}{*}{ PPG } & \multirow{4}{*}{ HDI } & \multirow{4}{*}{ HEA } & \multirow{4}{*}{ TMPTA } & & \multirow{4}{*}{$\begin{array}{c}\text { 4-(4-Aminophenyl) } \\
\text { Benzonitrile } \\
\text { (AB) }\end{array}$} & 0.5 & & AB05 \\
\hline & & & & & & 1.0 & & AB10 \\
\hline & & & & & & 1.5 & & AB15 \\
\hline & & & & & & 2.0 & & AB20 \\
\hline
\end{tabular}

aDC - Dispersed virgin clay

PUA:TMPTA:EHA $=4: 4: 2$ by weight 


\subsection{Measurements}

A Jasco Fourier Transform Infrared (FT-IR) 430 Spectrophotometer was used to observe the chemical modification of the clay at a resolution of $2 \mathrm{~cm}^{-1}$. Clay was grounded into $\mathrm{KBr}$ powder and pressed into discs prior to being placed in the FT-IR for scanning.

Transmitted light intensity was measured with a photodiode. The reference transmitted light intensity was obtained with blank cell of glass substrate. The output from a function generator was amplified and used to drive the shutter. The drive signal and the response of the photodiode were monitored with a digital storage oscilloscope (Hitachi VC6023) at ambient temperature. Morphology of the films was studied using scanning electron microscopy (SEM, Hitachi S430). For this, UV cured cells were fractured in liquid nitrogen and LC was extracted in ethanol for $24 \mathrm{~h}$ [16]. Contact angle of the resin surface with a drop of LC has been measured using a contact angle meter (G-1, Erma). X-ray diffraction (XRD) patterns for LCmodified clay system were recorded with symmetric reflection mode by using Rigaku X-ray Diffractometer $(30 \mathrm{kV}, 25 \mathrm{Ma})$. A monochromatic $\mathrm{CuK}_{\alpha}$ radiation was used. For each scanning interval of $2 \%$ min, diffracted X-ray intensity was automatically recorded.

\section{Results and discussion}

\subsection{XRD profiles}

Figure 2 shows XRD profiles of the virgin clay, hexylamine modified clay and 4-(4-aminophenyl) benzonitrile modified clay. The reflection peak at

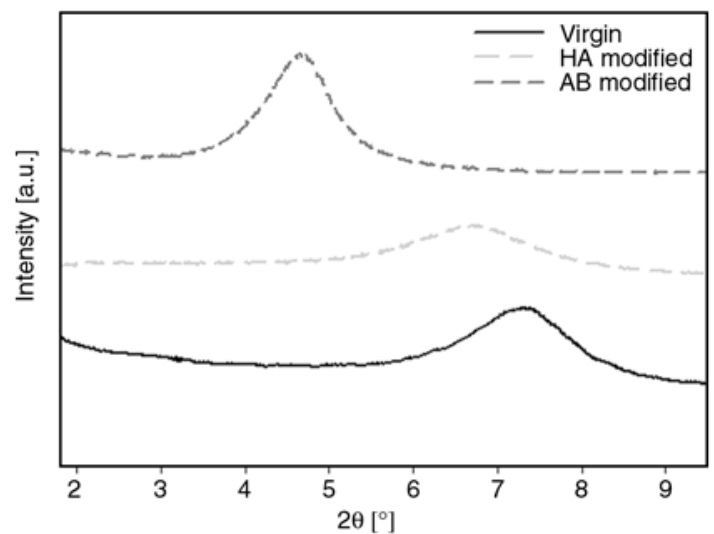

Figure 2. X-ray diffraction patterns of virgin clay, hexylamine (HA) modified and 4-(4-aminophenyl) benzonitrile $(\mathrm{AB})$ modified clay
$2 \theta=7.31^{\circ}$ gives the interlayer spacing ( $d$-spacing) of $12.07 \AA$ for the natural clay, which was calculated by Bragg's law (Equation (1)):

$\lambda=2 d \cdot \sin \theta$

where $\theta$ is the wavelength of $\mathrm{X}$-rays, $d$ is the spacing between the platelets of clay and $\theta$ is the diffraction angle. It is seen that the $d$-spacing is increased with the modified clay which is a direct indication of intercalation of LC molecules into the

a)

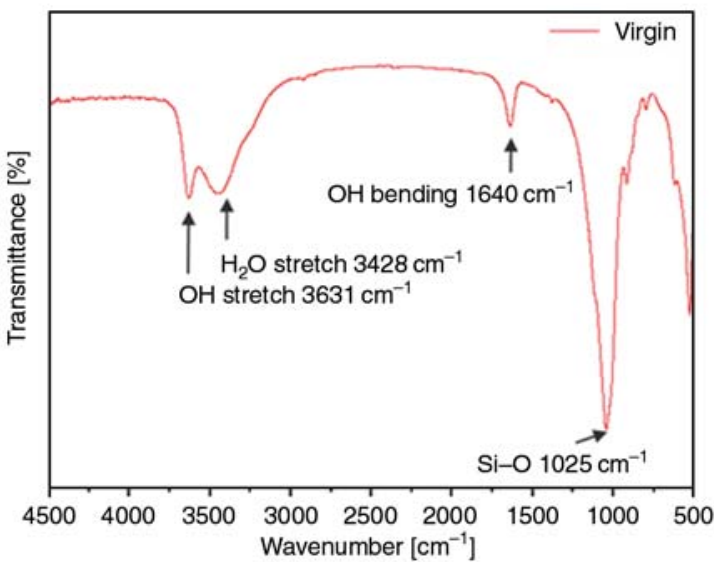

b)
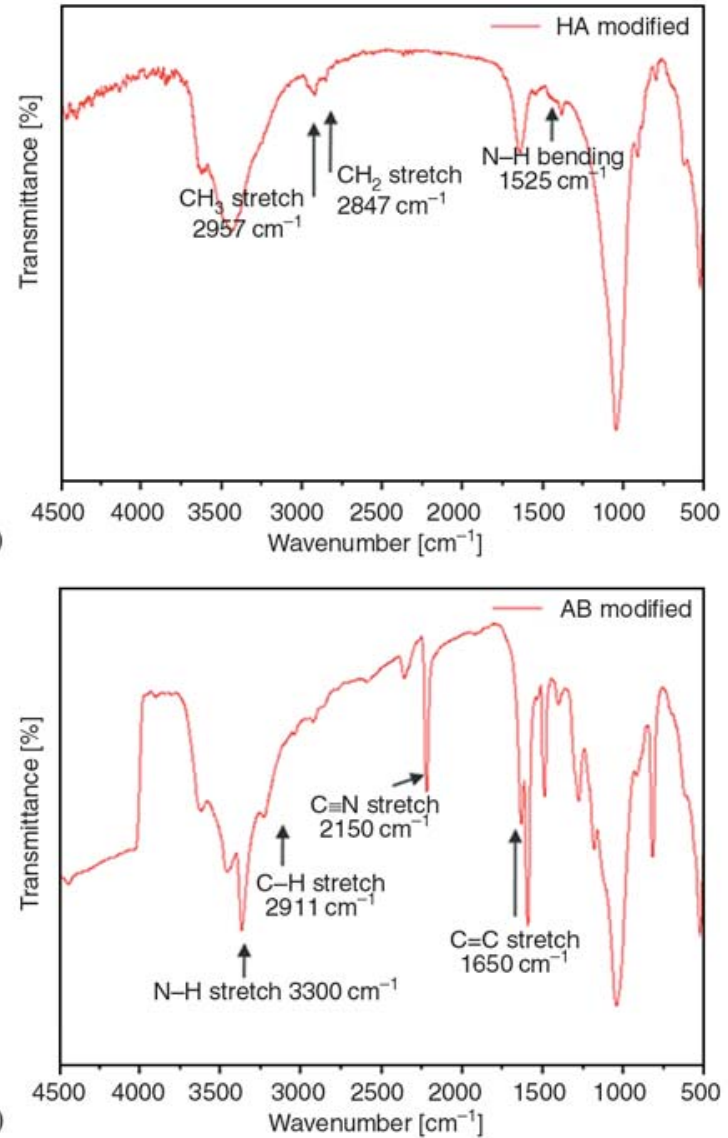

Figure 3. FT-IR spectra of virgin clay (a), hexylamine (b) and 4-(4-aminophenyl) benzonitrile modified clay (c) 
layered structures of clay. It is also seen that the effect is more pronounced with $\mathrm{AB}$ than with $\mathrm{HA}$ due to the larger molecular size of the former.

\subsection{FT-IR spectra}

The FT-IR spectra of the virgin and modified clays are shown in Figure 3. For the virgin Na-MMT (Figure 3a), the broad absorption band centered at $1025 \mathrm{~cm}^{-1}$ corresponds to different crystallographic sets of Si-Al-O layers. Also, the absorption bands of $\mathrm{OH}$ bending $\left(1640 \mathrm{~cm}^{-1}\right)$ and stretching (3400$3700 \mathrm{~cm}^{-1}$ ) vibrations are due to the hydroxyl groups of modified clay and absorbed water.

For hexylamine modified clay (Figure 3b), absorption bands with peak positions at 2847 , 2957 and $3300 \mathrm{~cm}^{-1}$ are assigned to stretching of $\mathrm{CH}_{2}, \mathrm{CH}_{3}$ and $\mathrm{NH}$ groups, respectively. The IR absorption spectra of 4-(4-aminophenyl) benzonitrile modified clay (Figure 3c) contain the bands of $\mathrm{C}=\mathrm{C}\left(1650 \mathrm{~cm}^{-1}\right), \mathrm{C}-\mathrm{H}\left(2911 \mathrm{~cm}^{-1}\right)$ stretching vibrations of benzene ring and $\mathrm{CN}\left(2150 \mathrm{~cm}^{-1}\right)$ stretching.

\subsection{Contact angle}

Contact angles of polymer matrix with an LC drop have been measured as a function of modified clay content and are given in Figure 4 which show that contact angle decreases with the addition and increasing amount of modified clay. It is also noted that the contact angle of $\mathrm{AB}$ modified clay is smaller than the HA modified one, implying that the biphenyl group commonly appearing in clay and LC molecules contribute to miscibility.

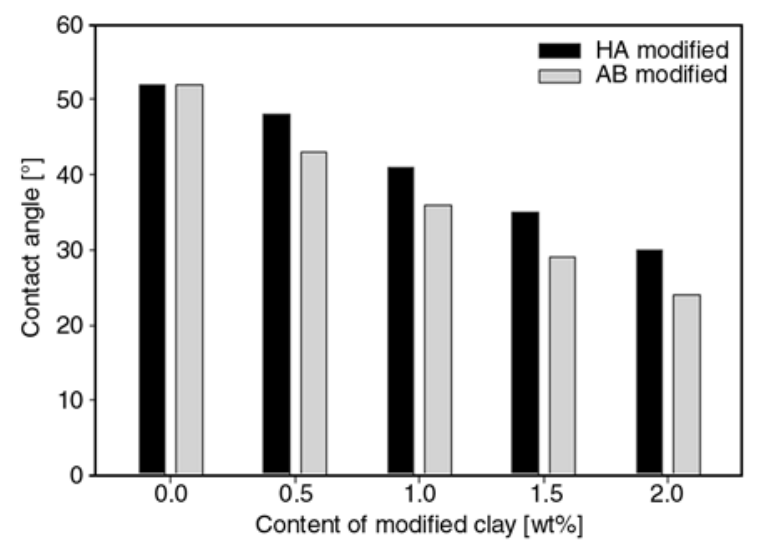

Figure 4. Contact angle of the film with LC drop
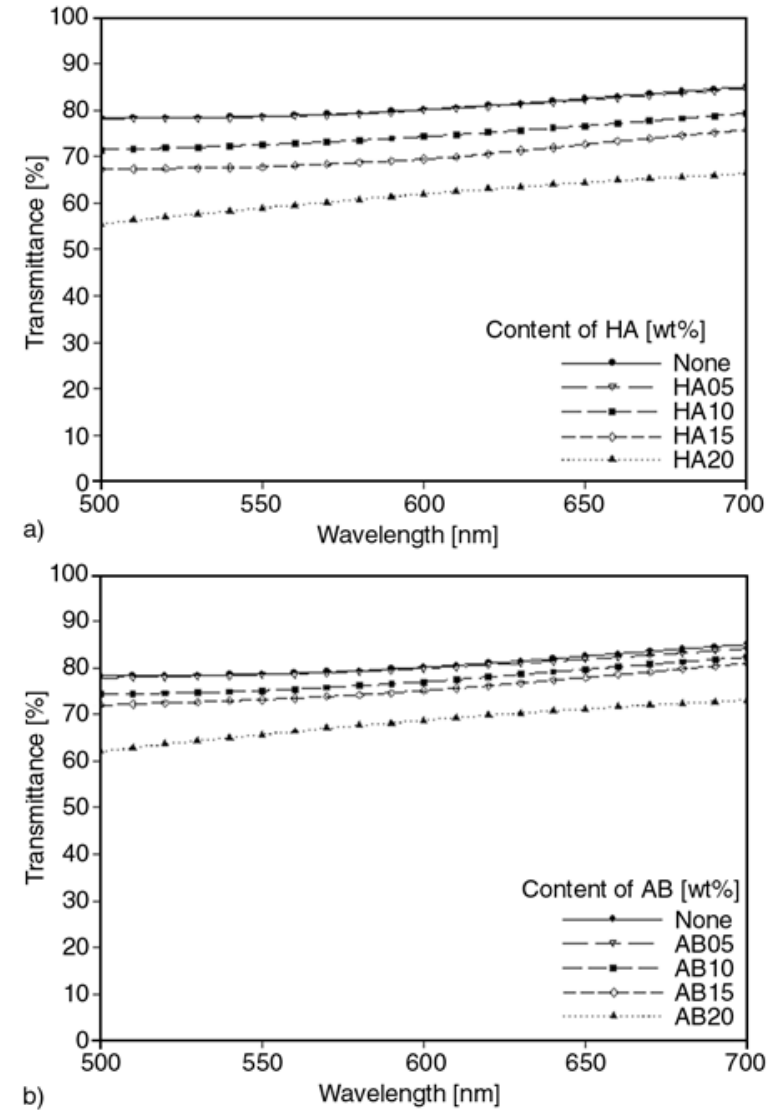

Figure 5. Visible spectra of various contents of HA (a) and $\mathrm{AB}(\mathrm{b})$

\subsection{Visible transmittance}

Visible transmittance of the films with different resin compositions is shown in Figure 5 for various contents of modified clay. It is seen that the transmittance is slightly decreased with addition and increasing amount of modified clay. Also, the transmittance of $\mathrm{AB}$ is higher than $\mathrm{HA}$ due to the better dispersion of $\mathrm{AB}$ in $\mathrm{LC}$.

\subsection{Electro-optical properties}

\subsubsection{Driving voltage and memory effect}

Typical switching characteristics of the film are shown in Figure 6 for various modifier contents, and parameters governing the effect are given in Table 2.

In the Table 2 memory parameter was defined by Equation (2):

$$
M=\frac{T_{m}-T_{0}}{T_{s}-T_{0}}
$$

where $T_{0}, T_{s}$ and $T_{m}$ are the initial transmittance of the sample, the transmittance of saturation in an 
electric field and the residual transmittance after removing the field, respectively [17]. So, higher $M$ gives greater memory effect. It is seen that the memory effect increases with the addition and increasing amount of modifier, and the effect is more pronounced with $\mathrm{AB}$.
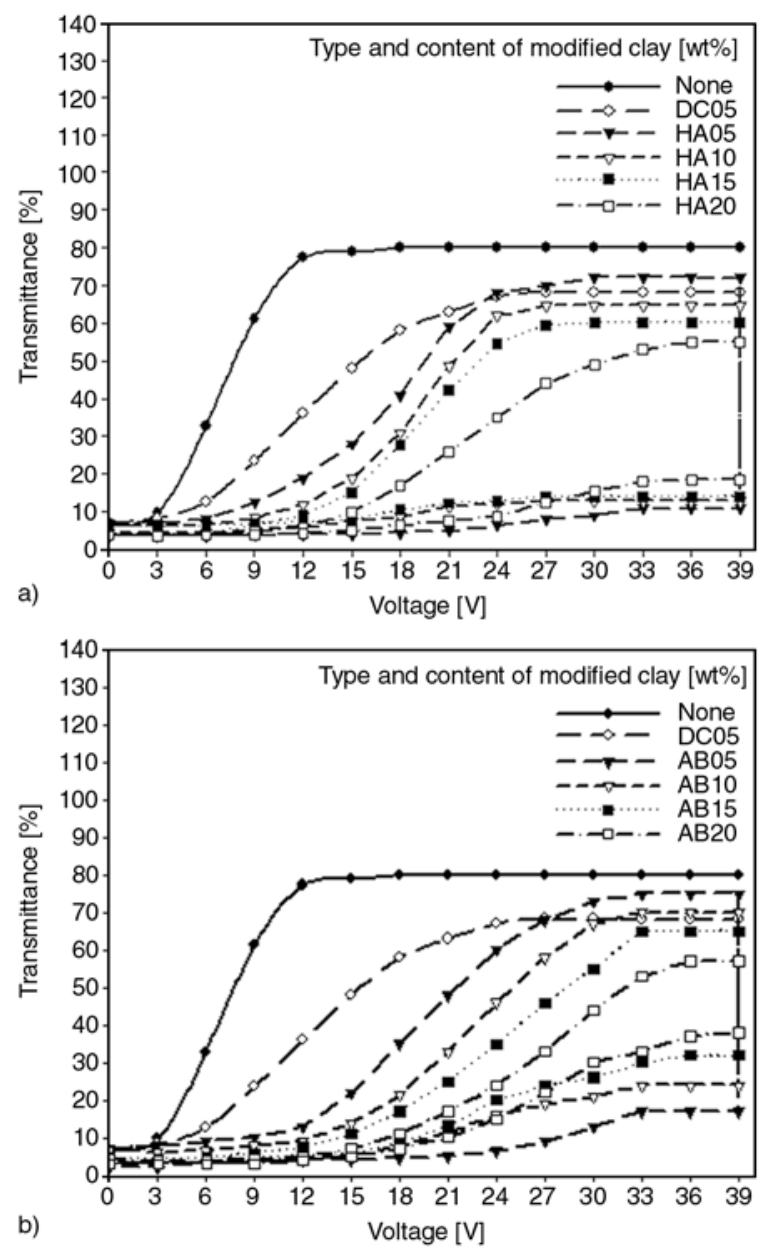

Figure 6. Transmittance vs. applied voltage at various contents of HA (a) and AB (b) (The upper and lower lines of the same caption respectively designate on state and off state transmittance. It is seen that films without clay and with virgin clay show no memory effect.)

Table 2. Memory effects of the film vs. type and content of clay

\begin{tabular}{|c|c|}
\hline Type and content of modifier & Memory parameter (M) \\
\hline None & 0.00 \\
\hline DC05 & 0.00 \\
\hline HA05 & 0.11 \\
\hline HA10 & 0.14 \\
\hline HA15 & 0.15 \\
\hline HA20 & 0.29 \\
\hline AB05 & 0.22 \\
\hline AB10 & 0.33 \\
\hline AB15 & 0.48 \\
\hline AB20 & 0.66 \\
\hline
\end{tabular}

It is seen that the driving voltage increases with the addition and increasing amount of modified clay due to the decreased droplet size to follow, which on the other hand is caused by the increased viscosity [18]. And the effect is more pronounced with $\mathrm{AB}$ than $\mathrm{HA}$ modifier.

\subsubsection{Response times}

The rise time is defined as the time required for the transmittance to increase from 10 to $90 \%$ points of the wave form upon turn on and the decay time is defined as the time required for the transmittance to fall from 90 to $10 \%$ upon turn off [19]. It is known that the reorientation field scales inversely with droplet size because the small liquid crystal domains produce high free energy of elastic deformations within the liquid crystal [20].

Typical response times of the films are shown in Figure 7, Table 3 and Table 4 for different types of clay and clay contents. Rise time and decay time increases with the addition and increasing amount of modified clay. These are due both to the decreased droplet size of LC (increased interfacial
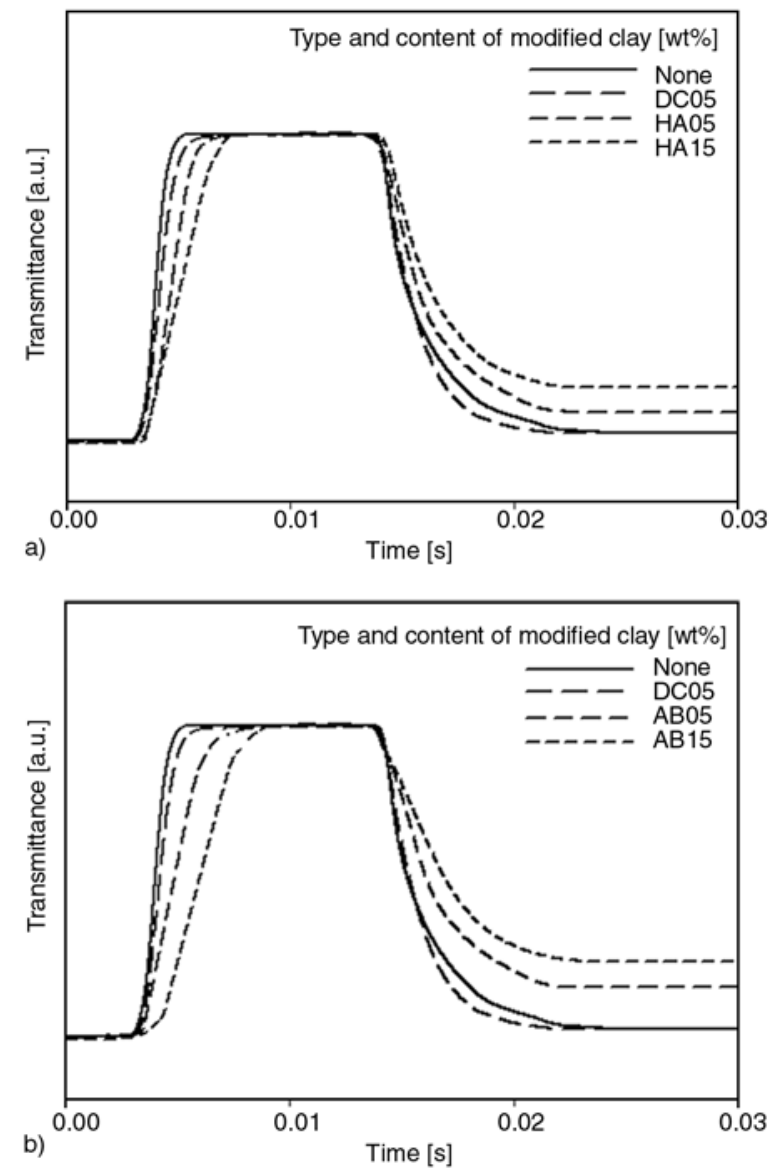

Figure 7. Response time vs. content of HA (a) and AB (b) 
area) and increased anchoring strength. The response time of $\mathrm{AB}$ is longer than $\mathrm{HA}$ due mainly

Table 3. Response time of the film vs. HA content (30 V)

\begin{tabular}{|c|c|c|}
\hline $\begin{array}{c}\text { Type and content } \\
\text { of modify agent }\end{array}$ & $\begin{array}{c}\text { Rise time } \\
{[\mathbf{m s}]}\end{array}$ & $\begin{array}{c}\text { Decay time } \\
{[\mathbf{m s}]}\end{array}$ \\
\hline None & 2.04 & 8.26 \\
\hline HA05 & 2.77 & 10.04 \\
\hline HA15 & 3.42 & 10.48 \\
\hline DC15 & 2.17 & 8.02 \\
\hline
\end{tabular}

Table 4. Response time of the film vs. AB content (30 V)

\begin{tabular}{|c|c|c|}
\hline $\begin{array}{c}\text { Type and content } \\
\text { of modify agent }\end{array}$ & $\begin{array}{c}\text { Rise time } \\
{[\mathbf{m s}]}\end{array}$ & $\begin{array}{c}\text { Decay time } \\
{[\mathbf{m s}]}\end{array}$ \\
\hline None & 2.04 & 8.26 \\
\hline AB05 & 3.02 & 10.51 \\
\hline AB15 & 3.91 & 10.82 \\
\hline DC15 & 2.17 & 8.02 \\
\hline
\end{tabular}

a)
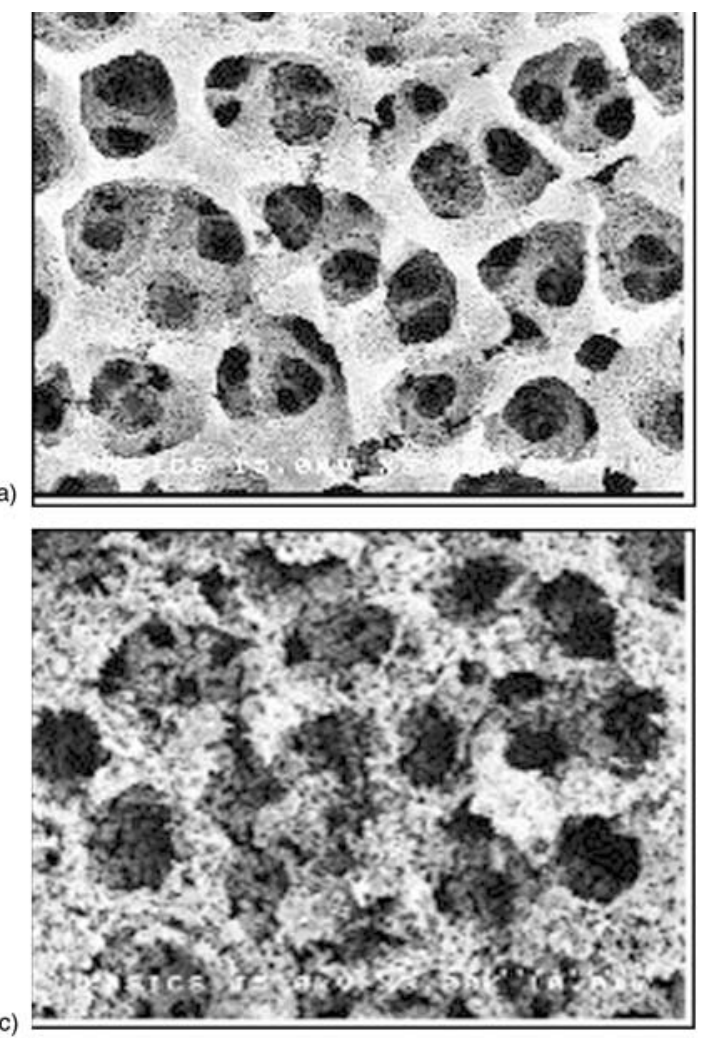

b)

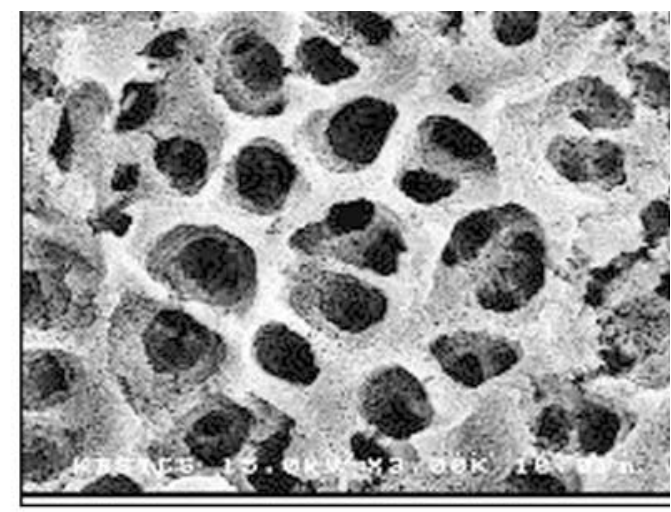

d)

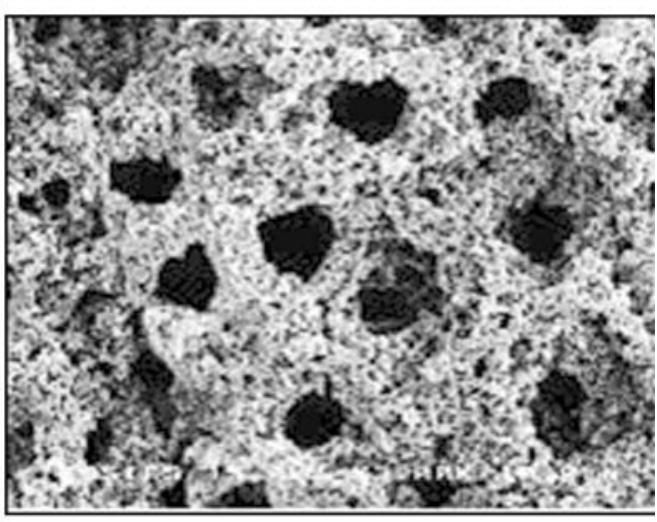

to the higher viscosity of AB. Virgin clay (DC) increases rise time over the None (AB00 and HA00) due to the increased viscosity, while the decay time decreased due mainly to the decreased droplet size of LC.

Surprisingly, the transparent state was maintained upon removal of the electric field, thus exhibiting memory effect. Upon field on, chain segments of modification are likely to orient along the field direction with LC molecules. Even after the field is off, the transmittance of the film remains high with modified clays and the effect is more pronounced with $\mathrm{AB}$ than HA modification. This implies that the modified clay maintains their orientation due to their bulkiness. Among the two types of modification, the pendant cyano-biphenyl group is expected

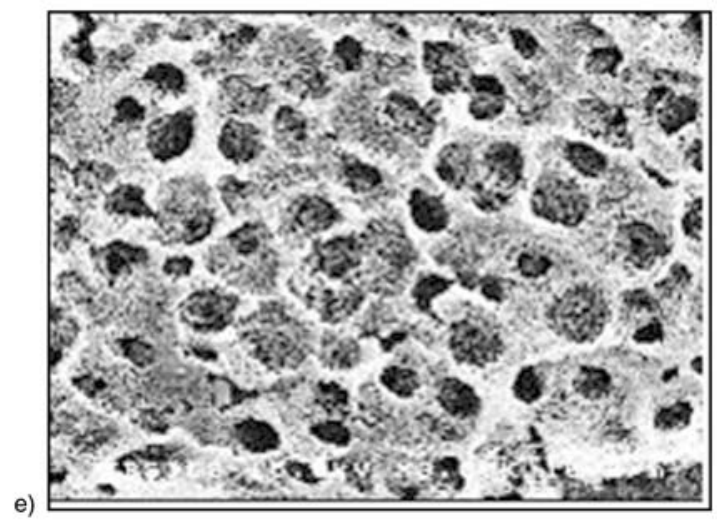

Figure 8. SEM image of the PDLC films vs. content of HA: 0 wt $\%$ (a), $0.5 \mathrm{wt} \%$ (b), $1.0 \mathrm{wt} \%$ (c), $1.5 \mathrm{wt} \%$ (d) and $2.0 \mathrm{wt} \%(\mathrm{e})$ 
to show greater effect than the straight alkyl chain (HA) in terms of bulkiness and viscosity. The driving voltage of $\mathrm{AB}$ is higher than $\mathrm{HA}$ due to its smaller droplet size by high viscosity.

\subsection{Morphology}

Figure 8 and Figure 9 show SEM morphology with $3.00 \mathrm{~K}$ magnification of the PDLC films as a function of the type and content of the modified clay. With the addition and increasing amount of modified clay, droplet size of LC monotonically decreases due to their high viscosity. The $A B$ shows smaller droplet size of LC than HA. This implies that miscibility of $\mathrm{AB}$ with $\mathrm{LC}$ molecules is

a)

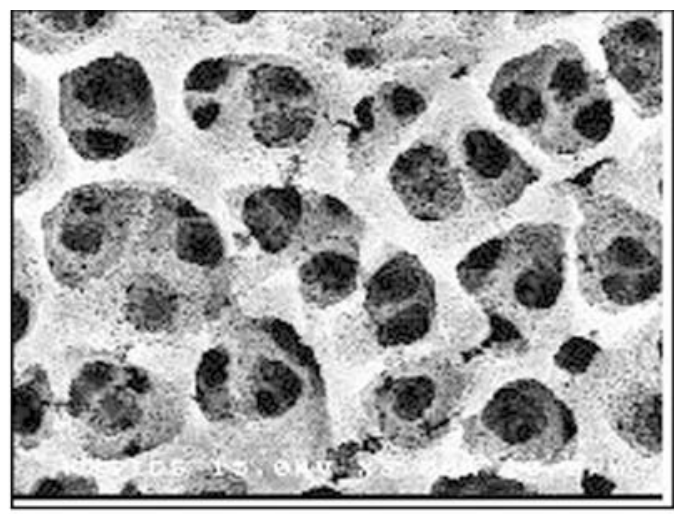

b)

greater than HA. At the same content of dispersed phase smaller droplet gives larger viscosity due to the larger effective volume of the droplet.

\section{Conclusions}

The addition of clay to the conventional polymer dispersed liquid crystals (PDLC) introduced significant effects in terms of morphology and electrooptical properties of the films. The memory effect exhibited by the modified clay is rather unusual since most of conventional nematic liquid crystals do not exhibit such effect.

With the addition and increasing amount of modified clay driving voltage and memory effect simul-
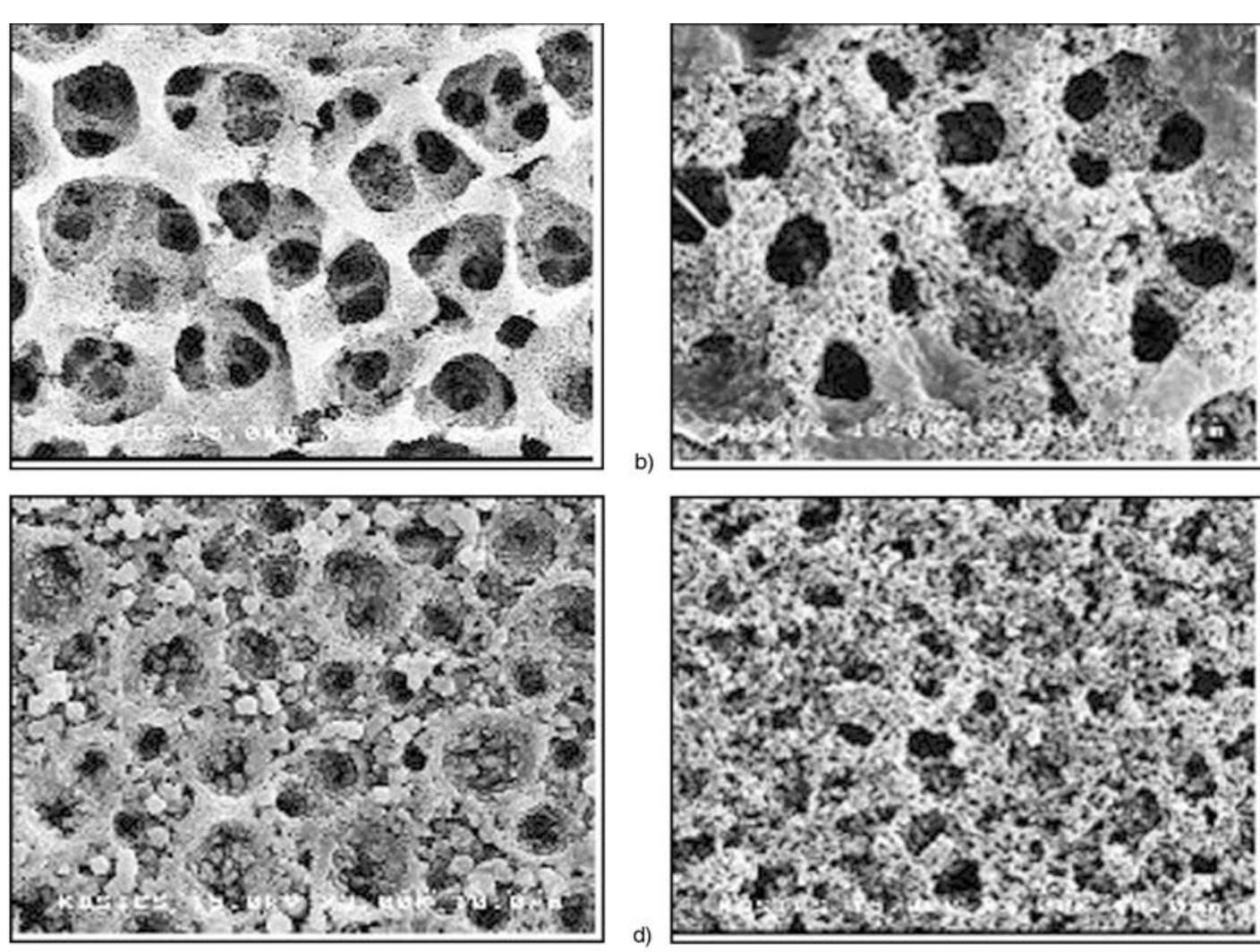

c)

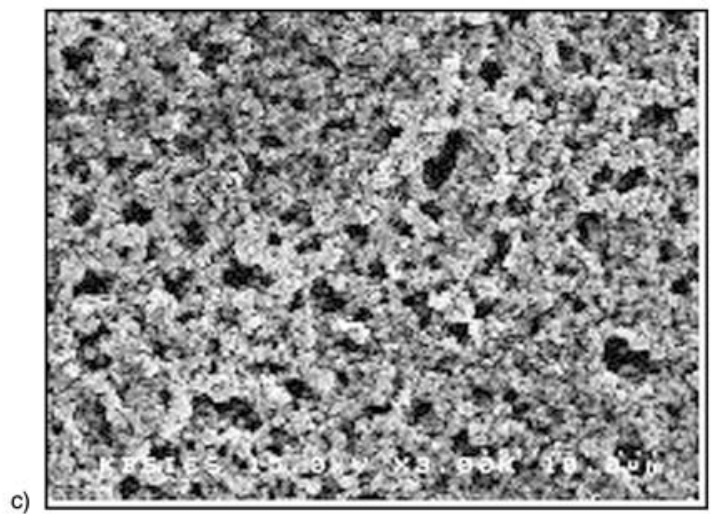

Figure 9. SEM image of the PDLC films vs. content of AB: $0 \mathrm{wt} \%$ (a), $0.5 \mathrm{wt} \%$ (b), $1.0 \mathrm{wt} \%$ (c), $1.5 \mathrm{wt} \%$ (d) and $2.0 \mathrm{wt} \%$ (e) 
taneously increased due to the increased viscosity. Among the two types of modifier, $\mathrm{AB}$ gave finer dispersion of clay in LC due to the greater miscibility of $\mathrm{AB}$ in $\mathrm{LC}$ than $\mathrm{HA}$. The greater miscibility is based on the similar chemical structure. So, AB gave greater viscosity, larger driving voltage and response time, and greater memory effect.

\section{Acknowledgements}

The research has been supported by the National Core Research Center at PNU.

\section{References}

[1] Drzaic P. S.: Polymer dispersed nematic liquid crystal for large area displays and light valves. Journal of Applied Physics, 60, 2142-2148 (1986). DOI: $10.1063 / 1.337167$

[2] Kawasumi M., Hasegawa N., Usuki A., Okuda A.: Nematic liquid crystal/clay mineral composites. Materials Science and Engineering: C, 6, 135-143 (1998). DOI: 10.1016/S0928-4931(98)00045-9

[3] Bunning T. J., Natarajan L. V., Tondiglia V. P., Sutherland R. L.: Holographic polymer dispersed liquid crystals (H-PDLCs). Annual Review of Materials Science, 30, 83-115 (2000). DOI: 10.1146/annurev.matsci.30.1.83

[4] Mucha M.: Polymer as an important component of blends and composites with liquid crystals. Progress in Polymer Science, 28, 837-873 (2003). DOI: $10.1016 / \mathrm{S} 0079-6700(02) 00117-\mathrm{X}$

[5] Fan Y-H., Lin Y-H., Ren H., Gauza S., Wu S-T.: Fastresponse and scattering-free polymer network liquid crystals for infrared light modulators. Applied Physics Letters, 84, 1233-1235 (2004). DOI: $10.1063 / 1.1649816$

[6] Nicoletta F. P., Chidichimo G., Cupelli D., Filpo G. D., Benedittis M. D., Gabriele B. G., Salerno A., Fazio A.: Electrochromic polymer-dispersed liquid-crystal film: A new bifunctional device. Advanced Functional Materials, 15, 995-999 (2005). DOI: $\underline{10.1002 / \mathrm{adfm} .200400403}$

[7] Puchkovska G., Reznikov Yu., Yakubov A., Yaroshchuk O., Glushcheko A.: Molecular interaction and 'memory' of filled liquid crystals. Journal of Molecular Structure, 404, 121-128 (1997). DOI: 10.1016/S0022-2860(96)09370-2

[8] Diorio N., Fisch M.: Filled liquid crystal depolarizers. Journal of Applied Physics, 90, 3675-3678 (2001). DOI: $\underline{10.1063 / 1.1401799}$
[9] Kang D., Maclennan J., Clark N., Zakhidov A., Baughman R.: Electro-optic behavior of liquid-crystal-filled silica opal photonic crystals: Effect of liquidcrystal alignment. Physical Review Letters, 86, 4052-4055 (2001).

DOI: 10.1103/PhysRevLett.86.4052

[10] Glushchenko A., Kresse H., Puchkovska G., Reshetnyak V., Reznikov Yu., Yaoshchuk O.: Memory effect and structure of filled nematic liquid crystals. Molecular Crystals and Liquid Crystals, 321, 15-30 (1998). DOI: $\underline{10.1080 / 10587259808025073}$

[11] Kawasumi M., Hasegawa N., Usuki A., Okada A.: Liquid crystal/clay mineral composites. Applied Clay Science, 15, 93-108 (1999). DOI: $\underline{10.1016 / \mathrm{S} 0169-1317(99) 00029-0}$

[12] Glushchenko A., Kresse H., Reshetnyak V., Reznikov Yu., Yaroshchuk O.: Memory effect in filled nematic liquid crystals. Liquid Crystals, 23, 241-246 (1997). DOI: $10.1080 / 026782997208505$

[13] Kim B. K., Lee J. C.: Waterborne polyurethanes and their properties. Journal of Polymer Science Part A: Polymer Chemistry, 34, 1095-1104 (1996)

DOI: $10.1002 /($ SICI $1099-0518(19960430) 34: 6<$ 1095::AID-POLA19>3.0.CO;2-2

[14] Kim B. K., Lee Y. H., Lee J. S.: Effect of polymer structure on the morphology and electro-optic properties of UV curable PNLCs. Polymer, 41, 1325-1335 (2000). DOI: $\underline{10.1016 / \mathrm{S} 0032-3861(99) 00282-7}$

[15] Jung J. A., Kim B. K.: Controls of solubility parameter and crosslinking density in polyurethane acrylate based holographic polymer dispersed liquid crystal. Optics Communications, 247, 125-132 (2005).

DOI: $10.1016 /$ j.optcom.2004.11.063

[16] Kim E. H., Kim B. K.: Diffraction gratings in noncrosslinked polymers. Journal of Polymer Science Part B: Polymer Physics, 42, 613-620 (2004). DOI: $10.1002 /$ polb.10743

[17] Puchkovskaya G., Reznikov Yu., Yakubov A., Yaroshchuk O., Glushchenko A.: Molecular interaction and 'memory' of filled liquid crystals. Journal of Molecular Structure, 404, 121-128 (1997). DOI: 10.1016/S0022-2860(96)09370-2

[18] Mormile P., Musto P., Petti L., Ragosta G., Villano P.: Electro-optical properties of a PDLC based on unsaturated polyester resin. Applied Physics B: Lasers and Optics, 70, 249-252 (2003). DOI: $\underline{10.1007 / \mathrm{s} 003400050040}$

[19] Klosterman J., Natarajan L. V., Tondiglia V. P., Sutherland R. L., White T. J., Guymon C. A., Bunning T. J.: The influence of surfactant in reflective HPDLC gratings. Polymer, 45, 7213-7218 (2004). DOI: $10.1016 /$ j.polymer.2004.08.043

[20] Wu B-G., Erdmann J. H., Doane J. W.: Response times and voltages for PDLC light shutters. Liquid Crystals, 5, 1453-1465 (1989). DOI: $\underline{10.1080 / 02678298908027783}$ 